7. Use of «Perseptron» algorithm to distinguish translational initiation sites in E. coll / G. D. Stormo, T. D. Scheider, L. Gold, A. Ehrenfucht // Nucl. Acids Res.--1985 - 13, ก $8 .-$ P. $2997-3011$.

8. Энхансероподобные структуры в умеренио повторяюпихся последователиностих эукариотилеских геномов / И. А. ІШахмурадов, Н. А. Колчанов, В. В. Соловьев, В. А. Ратнер // Генетика.-1986.-22, № 3.-С. $357-367$.

Ин-т ботаники п.. В. Л. Комарова АII А.зССР, Баку

Получено 10.05 .90

УДК 576.315 .42

В. В. ЈНатченко, А. Б. Бережнев

КАРТИРОВАНИЕ МЕСТ ПРИКРЕІЯЕНИЯ ДНК

К ЯДЕРНОМУ СКЕЛЕТУ

МЕТОДОМ ГРАФИЧЕСКОГО ПРЕДСТАВЈЕНИЯ

ПРОТЯभЕННЫХ НУКЛЕОТИДНЫХ ПОСЛЕДОВАТЕЛЬНОСТЕЙ

Методом графинскосо представления никлеотидных последовательностей в виде кривьх линий, отранаюицх распределение $A T-$ и GC-оснований по длине последовытельности. вьявлень характерные (S-образные) профили кривых, соответствуюице иестил крепления ДНК к ядерному скелету әукариот. Впервье показана примениность исиолизованного метода дая картирования ичастков связызамия ДНК со скелетнити стриктурами ядра. Тем самьм продемонстрирована возможность обнаружения функиионально однотипных негомологичных уиастков ДНК, ито не представляетсл возмонсньм с иомоцью других известных компьотерных методов анализа протяженных муклсотидных иоследоватсльностей.

Введение. $\mathrm{K}$ настоящему времени установлена первичая структура больпого числа генов и прилегающих к ним некодируюших областей ДНК. Поток такой информацин нарастает и требует осмысления. Анализ же структурно-функциональной организации генома сегодня несколько отстает от процесса накопления данных о псрвичных последоватсльностях. Поэтому определенную ценность представляет всякий свсжий подход, проливающий свст на выяснение функциональной значимости тех или иных участков последоватсльностсй.

Широкие возможности в этом плане открывают разнообразные компьютерные методы анализа последовательностей, позволяющие обрабатывать значительные массивы информации и представлять результаты в удобной для осмысления форме, например в виде графиков. Одним из перспективных подходов такого рода является метод графического прсдставлепия пуклеотидных последовательностсй, прсдложенный Хаморн [1], где для визуального анализа предлагается более дстальня картина, чем та, которая получается при глобальном анализе содержания GC-оснований. В последнем случае фиксируется лишь суммарный уровень $\mathrm{GC}$ - и АТ-оснований, имеющий биологический смысл (см., например, [2]). Кромс того, данный метод в нашем исследовании позволяет судить о функцाональном подобии нсгомологичных послсдовательностей ДНК путем установления схожести профилей получаемых с его помощью кривых линий, являясь своего рода графическим аналогом метода выравнивания. От выравнивания метод построения профилей нуклеотидных последовательностей отличает возможность эффсктивного сопоставления протяженных участков последовательностей, не обладающих к тому же близостью первичных структур, что бывает актуально в ряде случаев. В частности, при анализс хромосомной ДНК на предмет наличия мест прикрепления к ядерному скелету пами был использован данный метод как наиболес адекватный решаемой проблеме.

(C) B. B. IUMATUEHKO, A. Б. БEPEЖHEB, 1990 
ГІо современным представлениям, ДНК эукариотических клеток организована в виде многочисленных суперскрученных петель, основания которых прикреплены к скелетным структурам ядра (ядерному матриксу) или хромосомы (хромосомному остову) [3-6]. Средний размер петли ДНК составляет приблизительно 50 тысяч пар нуклеотидов (т. п. н.), а районы прикрепления ДНК к ядерному скелету имеют размер несколько сотен пар нуклеотидов $[3,4,7]$. Известно, что места

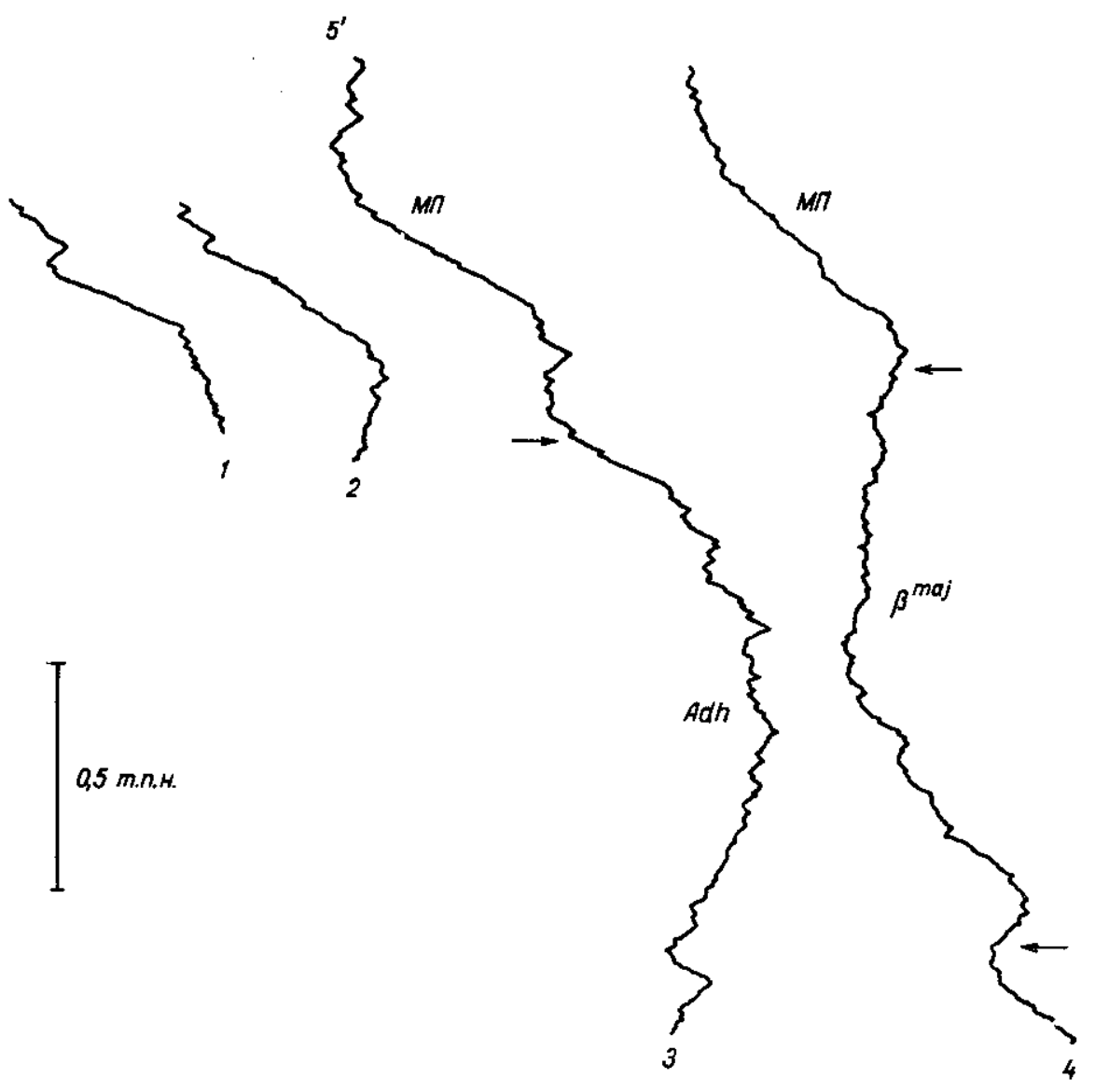

Рис. 1. Графическое представление нуклеотидных последовательностей: часть гена дигидрофолатредуктазы, прочно связанная с ядерным матриксом клеток хомяка $(1)$; 5 '. фланкирующая область гена Sgs4 D. melanogaster (2); ген алкогольдегидрогеназы $D$ melanogaster (3); $\beta$-глобиновый ген мыши (4). МП-место прикрепления ДНК к ядерному скелету. Стрелками указаны границы генов

Fig. 1. Graphic representation of nucleotide sequences: matrix attachment region of hamster dihydrofolate reductase gene (1); 5 -flanking sequence of Drosophila Sgs4 gene (2); alcohol dehydrogenase gene of Drosophila melanogaster (3); mouse $\beta$-globin gene (4). $M \Pi$-- matrix association region. Arrows point the boundarics of genes.

прнкренлияя обогащены АТ-основаниями и, как правило, располагаютея в исжгенных некодируемых областях хромосомной ДНК [7-9]. Домен1:1я органпзация генома псобходима для поддержанця компактного состояния ДНК и, по-видимому, играет важную роль в процессах репликцин и регуляции генной активности $[6,8,10]$.

В пастоящей работе для картирования областей прнкрепления ДНК $к$ ядерному скелету применяли компьотерную программу PROFIl.E (НБФМ AH СССР), реализующую а.Iгорнтм ностроспия графпков пукисотидинх постедовательностей на IВM РC-совместимых компьютера. 13 печеств источника последовательностей ДНК мы псполь-

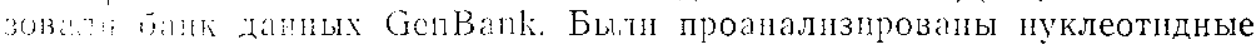


последовательности огранизмов, представляющих различные таксономические группы. Показано соответствие характерных $S$-образных профилей участкам ДНК, отвечаюцим за связывание с ядерным скелетом.

Материалы и методы. Для построения графиков послсдоватсльностсй ДНК примеıяли подход Хамори [1]. Согласно этому методу, нуклеотидные остатки последовательности рассматриваются в качестве фиксированных векторов, состыкованных друг с другом по принципу «голова - хвост». Векторы вычерчивают в трехмерном пространстве кривую линию, полностью отражаюцую распределение этих нуклеотидных остатков в последовательности ДНК.

В ґастоящей работе мы использовали вариант метода графического представления последовательностей, в котором из стереометрической пары изображений, дающих в совокзпности объемную картину, применяли лишь одно из изображений последовательності ДНҚ. Подобный метод применяли, в частности, в работе Хамори [11].

Алгоритм графического представления последовательностей путем вычерчивания соответствующих профилей был реализован в ИБФМ АН СССР в виде компьютерной программы PROFILE на языке CИ примснительно к IBM PC-совмсстимым компьютерам.

Последовательности ДНК, начиная с $5^{\prime}$-конца, преобразовывали в кривыс, вычерчивание которых натинали с верхней части графика, откладывая влево и вниз отрезки, соответствующие G- и C-основаниям, а вправо и вниз-соответствующие $A-$ и Т-основаниям.

Для анализа использовали также программу пот-матричного анализа DNASEQ (ИБ АН СССР) и программу анализа нуклеотидных и аминокислотиых последовательностей DM5 (Аризонский университет, США).

Последовательгости ДНК получили из 55-го выпуска банка данных GenBank.

При работс использовали компьютер Правец-16А (Болгария). Вычерчивание профи.тей нуклеотндных последовательностей проводили на плоттере МИКРОНИКА ПР 297 (Болария) и принтере Robotron К 6314 (ГДР).

Результаты и обсуждение. К настояцему времени в окрестностях различыых генов высших организмов экспериментально локализованы участки прикреплепия ДНК к ядерному скелету, общим свойством которых является их АТ-богатый состав $[7-9,12,13]$. В ходе работы мы сравнили профили кривых, получаемых в результате графического представления дапных участков ДНК.

На рис. 1 кривые 1 и 2 соответствуют участкам последователынсreï ДНК, которые крепятся к скелетным структурам: часть гена дигидрофолатредуктазы хомяка [13] (кривая 1) и 5'-флапкируюшая область гена Sgs4 Drosophila melanogaster [9] (кривая 2).

На рис. 1 также представлены профили нуклеотидпой последовательшости гена алкогольдегидрогеназы D. melanogaster (кривая 3) и $\beta$-глобинового гена мыши (кривая 4). Согласно эксперименталыным данным [9, 14], 5'-копцевые области этих генов прилегают к ядерному матриксу.

Как вигно из графика, кривые 1 и 2 , а также $5^{\prime}$-концевые участки кривых 3 и 4 , соответствующие районам прикрепления ДІІК к ядерному скелсту, имеют сходиый профиль. Похожий профиль мы наблюдали и в ряде других аналогичных случаев. Всего было проанализировано 14 последовательностей ДНК, т. е. практически все известные к пастоящему времепи последователыости, для которых устаповлены места крепления к ядерному матриксу (данные не представлены).

Применяемый пами метод дает возможность более детально проапализировать участки, соответствующие местам крепления ДНК к я,церіому матриксу, для которых обычно указывается лиць процентное содержание АТ-оснований. Графитеский метод выявляет детальное распределение AT- и GC-оснований по длине этих участков: центральный район с высоким уровнем содержания АТ-оснований и более короткие флапкирующие отрезки, относительно равномерно насыщенные как AT-, так и GС-основаниями. Соответствующие данным участкам профили имеют характерный $S$-образный вид. 
В свого очередь, наличие характерных $S$-профилей дает возможность визуального выявления потенциальных мест прикрепления ДНК к ялдерному скелсту. Дополнительным подтверждением соответствия выявляемых участков предполагаемой функции может быть паличие на этих участках сайтов узнавания топоизомеразої II. Поскольку, как известно, основным белковым компонентом ядерного матрнкса [15] и

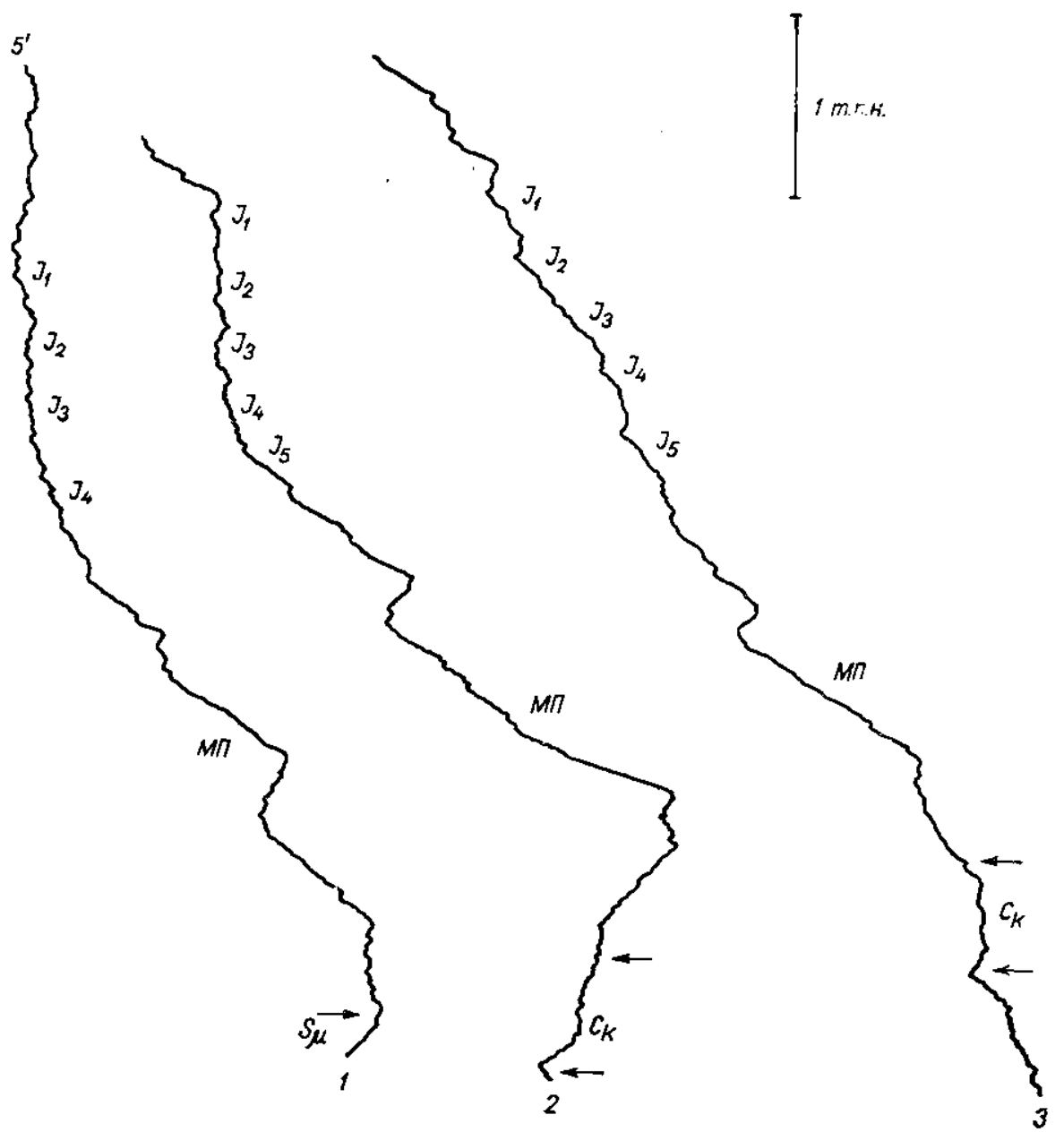

Рис. 2. Сравнение кривых, соответствующих локусам иммуноглобулиновых генов: ген $\mu$-цепи иммуноглобулинов мыши $(I)$; ген $x$-цепи иммуноглобулинов кролика (2); ген, кодирующий $x$-цепь иммуноглобулинов мыши (3). МП-место лрикрепления ДНК к ядерному скелету. Стрелками указаны границы генов

Fig. 2. The comparison of curves corresponding to immunoglobulin gene loci: mouse mu immunoglobulin (1); rabbit kappa immunoglobulin (2); mouse kappa immunoglobulin (3). $М \Pi-$ matrix association region. Arrows point the boundaries of genes.

хромосомного остова [16] является топоизомераза II, а участки ДНК, прилегающие к указанным скелетным структурам, имеют последовательности, которые узпаются этим ферментом.

В целях изучения возможности предсказания потенциально однотипных по выполняемой функции районов на примере мест связывапия ДНК с ядерным матриксом сравнивали профнли нуклеотидных последовательностей родствепных генов. Для этого были выбраны эмбрионалыные гены иммуноглобулинов мыши с экспериментально установленными местами прикрепления, а также аналогичный ген кролика, где данный функциогальный район не установлен. 
Гр)афическиї профинь послсдовательностп ДНК, кодирующсй $\mu$-цепь нммуногобулина мыни (рнс. 2 , кривая 1 ), имсет характерный $S$-образиый гін; в той части криной, которая соответствует месту связывапня ДиК с ядерным скелетом. Место крепления ДНК в даниом случае расположено в больинм питроне указанного генетінеского локуса [12].

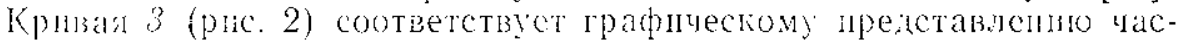
ти гелетилеского покуса, кодируюпего $\%$-цепл мышиных пммунолобулнио [17]. Как вн,шюо из графика, в пределах данного участка генома в питроне межлу ссмсйствами $J$-генов и $C$-геном имеется $S$-профиль, соответствующий үтастку прикрепления ДНК к ядерному скелету [8].

Крпвая 2 (рис. 2) представияет собой графпческое изображение renа $x$-цепи иммуноглобулина кролика [18]. На участке кривой, соответствующей больному питропу этого гена (между J5-сегментом и $C$ гепом), обнаруживается характсрный $S$-профиль.

Кроме того, в данпом участке ДНК (рис. 2, кривая 2) имеются три сайта Узнаваня топонзомеразой II (поиск вели по канонической послсдовательности дія топопзомеразы II $D$. melanogaster GTN $(\mathrm{A} / \mathrm{T}) \Lambda(\mathrm{T} / \mathrm{C}) \operatorname{ATTNATNN}(\mathrm{G} / \mathrm{A})$ [19]). Хотя эксперимегтальные дапие о соответствин этого утастка месту связывания ДНК с ядерным матриксом отсутствуют, можно предположнть, что оп выполпяет имеппю) такую фупкцио.

Помимо графического построения мы провели сравнеиие псрвичных структур угастков прнкрепления ДНК методом дот-матричного апализа. IІри заданных условнях сравнения последовательностей (не менсе 13 совпаденпй в окпе из 15 оснований) гомология этих утастков ДНК пе выявлепа (дапые не приведепы).

Таклм образом, мето:, примененый в настоящей работе, позволяет картировать функцинально подобные участки на протяжениых после:бозательностях ДНК (в том тисле имеюшие различные первичпые структуры при одной и той же бнологической фупкции, как это было продемонстрировано нами на примере анализа мест прикреплепня ДІК к ядерному скелету). Даный метод может служить основой для скриннга бапков нуклеотидных последовательностсй путем визуального раснозиавания функциолально значимых участков генома.

\section{MAPPING DNA ATTACHMENT SITES ON NUCLEAR FRAME BY GRAPHIC REPRESENTATION OF LONG DNA SEQUENCES}

V. V. Schmatchenko, A. B. Berezhnev

Institute of Biochemistry and Physiology of Microorganisms, Academy of Sciences of the USSR, Pushchino, Moscow region

Su m m a I y

Characteristic (S-form) curves corresponding to nuclear matrix association regions have been revealed by graphica!ly represented DN $\Lambda$ sequences. The curves reflect $\mathrm{AT}$ and GC distribution along the sequence length. The method is applicable for mapping DNA attachment sites on nuclear framc. Functionally identical nonhomologous DNA regions in long sequences can be detected which is impossible using other computer-assisted methods of nucleotide sequence analysis.

\section{СПИСОК ЛИТЕРАТУРЫ}

1. Hamori E., Ruskin J. H curves, a novel method of represcntation of nucleotide series especially suited for long DNA scquences//J. Biol. Chem.-1983.-258, N 2.P. $1318-1327$.

2. Ikemura $T$., Aota $S$. Global variation in $\mathrm{G}+\mathrm{C}$ content along vertebrate genome DNA. Possible correlation with chromosome band structures//J. Mol. Biol.- $1988 .-203$, N 1.-P. 1-13.

3. Benyajati $C$., Worcel $A$. Isolation, characterization and structure of the folded interphase genome of Drosophila melanogaster // Ccll.-1976.-9, N 3.- P. 393-407.

4. Paulson $J$. R., Laemmli $U$. K. The structure of histone deplete metaphase chromosomes // Ibid. - 1977. - 12, N 5.- P. 817-828. 
5 Vogelstein B., Pardoll D. M., Colfey D. S. Supercoiled loops and eukaryotic DNA replication // Ibid.-- 1980.-22, N i.- P. $79-85$.

6. Georgiev G. P., Nedospasov S. A., Bakayev V. V. Supranucleosomal levels of chroma. tin organization // The Cell Nucleus.-1978.-6, N 1.- P. 3-34.

7. Mirkovitch J., Mirault M.E., Laemmli U.K. Organization of the higher-order chromatin loop: Specific DNA attachment site on nuclear scaffold//Cel1.-1984.-39, N 1.-P. 223-232.

8. Cockerilt P. N., Garrard W. T. C. Chromosomal loop anchorage of the kappa immunoglobulin gene occurs next to the enhancer in a region containing topoisomerase II sites // Ibid.-1986.-44, N 2.-P. 273-282.

9. Gasser $S$. M. Laemmli $U$. K. Cohabitation of scaffolding binding regions with upstream/enhancer elements of three developmentally regulated genes of $D$. melanogaster // Ibid. - 46, N 3.- P. $521-530$.

10. Dijkwel P. A., Hamlin J. L. Matrix attachment region are positioned near replication initiation sites, genes, and an interamlicon junction in the amplified dihydrofolate reductase domain of chinese hamster ovary cells//Mol. and Cell. Biol.-1988.-8, N 12 - P . 5398-5409

11. Hamori E., Varga G. DNA sequence (H) curves of the human immunodeficiency virlis 1 and some related viral genomes // DNA.-1988.-7, N 5.-P. 371-378.

12. Cockerill P. N., Yuen M.-H., Garrard W.T. The cnhancer of the immunoglobulin heavy clain locus is flanked by presumptive chromosomal loop anchorage elements // J. Biol. Chem-1987.-262, N 11.- P. 5394-5397.

13. Kas E., Chasin L. A. Anchorage of the chinese hamster dihydrofolatc reductase gene to the nuclear scaffold occurs in an intragenic region//J. Mol. Biol.-1987.-198, N 4.- P. 677-692.

14. Greenstein R. J. Constitutive attachment of murine crythroleukemia cell histone depleted DN $\Lambda$ loops to nuclear scaffolding is found in the $\beta$-major but not the $\alpha 1$-globin gene // DNA - 1988-7. N 9.- P. 601-607.

15. Berrios M., Osheroff N., Fisher P. A. In situ localization of DNA topoisomerase II, a major polypcptide component of the Drosophila nuclear matrix fraction// Proc. Nat. Acad. Sci. USA.- 1985.-82, N 13.- P. 4142.4146.

16. Metaphase chromosome structure. Involvement of topoisomerase II/S. M. Gasser, T. Larochc, J. Falquet et al.//J. Mol. Biol-1 1986.-188, N 3.- P. 613-629.

17. Max E. E., Maizel J. V., Jr., Leder P. The nucleotide sequence of a 5,5-kilobase DNA segment containing the mouse $x$ immunoglobulin $J$ and $C$ region genes//J. Biol. Chem-1981-256, N 10.- P. 5116-5120.

18. Emorine L., Max E. E. Structural analysis of a rabbit immunoglobulin $\times 2 J-C$ locus revcals multiple deletions // Nucl. Acids Res.-1983.-11, N 24.-P. 8877-8890.

19. Sander M., Hsieh T.-S. Double strand DNA clcavage by type II DNA topoisomerase from Drosophila melanogaster//J. Biol. Chem.-1983.-258, N 15.- P. 8421-8428.

Ин-т бнохимни и физиологни микроорганизмов АН CССР,

Полугено 11.03 .90 I IVHนHН

УДК 576.315 .42

\section{В. В. Волков, А. Ю. Леонтьев}

\section{ИССЛЕДОВАНИЕ СИММЕТРИИ ГЕНЕТИЧЕСКИХ ТЕКСТОВ МЕТОДОМ ФУРЬЕ-АНАЈИЗА}

$B$ работе предложен метод классификацин симиетринных структур одноиепочечной

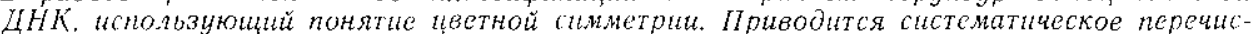
ление нветных точечньх и пространственнох групп. Дая поиска структир с инверсионной симметрией предлагается использовать фурье-анализ с фильтрацией. основанной на сикистриной иисловой кодировке нуклеотияной последовательности. Прямье повторо обнаруаниваются с помощью фурье-анализа кан первого этапа поиска, сушественно сокранынынеzо tисло операций сравнения. Методы опробованы на модельных последова-

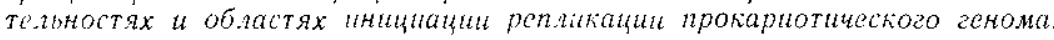

В настояцее время общеизвестно, что такие фуцкциональные сайты, қак точка начала репликащии, сайты узпавания рестриктаз, сайты терминации транскрипци, энхансеры и другие являются симметричными структурами либо обогащены ими (см., например, [1-4]). Поэтому одним из этапов выявлепия функциональных сайтов в генетических текстах является лоиск симметричных структур в молекуле ДНК.

(C) В. В. ВОЛКОВ, А. Ю. ЛЕОНТЬЕВ, 1990 